\title{
Effects of electroconvulsive shock upon conditioning and extinction of a free operant in rats
}

\author{
IGNACIO MORGADO-BERNAL \\ Behavior Laboratory, Autonomous University of Barcelona, Barcelona, Spain \\ and \\ LLUÍS GARCIA-SEVILLA \\ Abnormal Psychology Laboratory, University of Barcelona, Barcelona, Spain
}

\begin{abstract}
A group of rats was treated with a double electroconvulsive shock (ECS) applied contingently after conditioning sessions on a continuous reinforcement (CRF) schedule. The rats were allowed to make 20 responses per session. Another group of subjects not treated with ECS was used as a control group. Later, two long CRF sessions without treatment were given to equate the experimental and control groups. Following this training, all animals received three extinction sessions. The two first sessions were followed by a double ECS for half of the subjects in each group (control and experimental). Different rates of conditioning and extinction were studied. In acquisition, an ECS effect was observed which increased with successive treatment and had an opposite trend to the practice effect. In extinction, ECS did not have a significant effect, although a similar trend was observed.
\end{abstract}

The majority of studies that have attempted to determine the effect of electroconvulsive shock (ECS) on animal learning have been carried out employing avoidance conditioning procedures which allow rather precise control of the possible variables operating a given experiment (Duncan, 1949). Generally, the results show that ECS decreases avoidance response rates (Duncan, 1949; Miller, 1968; Missanin, Smith, \& Miller, 1971; Thompson \& Dean, 1955). There are some studies where the ECS is applied contingently to conditioning sessions using positive reinforcement, with results which seem, generally, opposite to those found with avoidance tasks. That is, after administering an ECS, the positively reinforced response has increased instead of decreasing (Gauscillo, 1971; Keyes, 1973; Keyes \& Young, 1973; Routtenberg \& Kay, 1965).

Studies attempting to clarify the effects of ECS on extinction are even more scarce. Dempsey and Young (1973) showed that the ECS applied after an extinction of positive reinforcement did not decrease the resistance to extinction in a later session.

As can be seen, the effect of ECS on appetitive conditioning does not seem to have the same trend as it has on aversive conditioning. With aversive conditioning situations, the ECS appears to interfere

Requests for reprints should be sent to Ignacio Morgado, Laboratorio de Conducta, Departamento de Psicología, Facultad de Letras, Universidad Autónoma, Bellaterra (Barcelona), Spain. with retention, while in appetitive conditioning tasks ECS may enhance it; however, this last effect requires more experimental support. With reference to the extinction of both kinds of conditioning, the lack of empirical data does not allow any conclusion yet. For this reason, the present study consists in the administration of an ECS treatment on both learning and extinction of a free operant with positive reinforcement.

\section{METHOD}

\section{Subjects}

The subjects were 50 male Sprague-Dawley rats about 150 days old at the beginning of the experiment. They were maintained at $80 \%$ of their free-feeding weights (300-350 g) by food deprivation.

\section{Apparatus}

The essential components of the system used consisted of: a standard Skinner box with a cumulative recorder (Gerbrands), a programmer (Garcia \& Morgado, 1976), and an ECS generator unit (Basile, N-76770). Positive reinforcers were 45-mg Noyes food pellets.

\section{Procedure}

After a magazine training session, the rats were shaped to press a lever for food. When they emitted the first 20 responses on a continuous reinforcement (CRF) schedule, they were quickly taken out of the experimental chamber and immediately given two $100-\mathrm{mA}, 500-\mathrm{Hz}$ sine-wave ECS treatments of $2 \mathrm{sec}$ duration, with a 10-sec interval between each single ECS. On 3 following days, the animals received a daily session of 20 reinforced responses. At the end of each session, except on the 3rd day, the rats received the double ECS treatment. Half the subjects never received any ECS, and these were used as a control group. 
On the 5th and 6th days, all subjects were given a daily session of 200 reinforced responses, in order to equate the response rates of the control and experimental groups. On the subsequent 3 days, each animal received a 10-min extinction session. Half the animals in each group (control and experimental) received the double ECS treatment at the end of the first two sessions of extinction. Half the animals in each group did not receive any ECS.

\section{RESULTS}

In order to take into account individual differences in barpress conditioning (Garcia-Sevilla \& Garau, 1978), the dependent variable was referred to the original response rate (required time for the 20 responses $\times 100 /$ time of shaping). Eleven subjects that did not emit the 20 first responses within the first 15 min of the shaping session were eliminated.

The required time for the 20 responses in the treated animal tended to decrease less in each session than the time for the untreated animals. Two-factor (ECS and session) analysis of variance with replications showed only an ECS effect $(F=9.05, \mathrm{df}=1 / 111$, $p<.01)$. $t$ tests $(d f=37)$ were performed between treated and not treated groups for each of the three conditioning sessions after shaping: first session, $\mathrm{t}=.877$, n.s.; second session, $\mathrm{t}=2.761, \mathrm{p}<.01$; third session, $\mathrm{t}=2.25, \mathrm{p}<.05$.

After the two retraining sessions (200 reinforced responses on CRF without treatment), there were no significant differences between the groups (treated and control) on the 1 st day of extinction $(t=.72$, n.s.).

In order to neutralize the individual differences in extinction, the following formula was used: nonreinforced responses $\times 100 /$ nonreinforced responses in the first extinction session. In the second and third extinction sessions, the response rate of the experimental groups was higher than the rate of the controls. However, a two-factor (ECS and session) analysis of variance with replications showed only a session effect $(F=14.47, \mathrm{df}=1 / 74, \mathrm{p}<.01)$.

\section{DISCUSSION}

\section{Conditioning}

After shaping, a weak difference between the control and the experimental group was found, which did not attain significance until after the second session. For this reason, we conclude that, under the conditions of our experiment, the ECS effect is weak, of cumulative character, and always opposite to the practice effect. In Hullian terms (Hull, 1943), the ECS effect decreases the habit strength. These findings support the consolidation hypothesis of Duncan (1949) and they agree with the ECS effect on aversive conditioning (Gauscillo, 1971; Keyes, 1971).

\section{Extinction}

After retraining sessions, the experimental and control groups were matched as there were no significant differences in the response rate on the first extinction session. The results obtained in the second and third extinction sessions showed a trend in the same way that was noticed on conditioning. In Hullian terms, we could say that ECS decreases the "negative habit" strength $\left({ }_{s} I_{r}\right)$, thus increasing the resistance to extinction. In the third session, a more pronounced trend is noted, which supports the cumulative character that we are attributing to the ECS effect. The fact that these differences were not statistically significant could be attributed to the weak effect of treatment (as we noted for the conditioning), and being the ECS effect opposite to the session variable, the effect of treatment could be hidden by the strong effect of the session one.

\section{REFERENCES}

Dempsey, G. L., \& Young, A. G. The effect of electroconvulsive shock on extinction. Bulletin of the Psychonomic Society, 1973, 1, 129-131.

Duncan, C. P. The retroactive effects of electroshock on learning. Journal of Comparative and Physiological Psychology, 1949, 42, 32-44.

Garcia-Sevilla, L., \& Garau, A. Extraversion y deambulación de la rata en el Campo Abierto. Revista Latinoamericana de Psicologia, 1978, 10, 211-226.

Garcia-Sevilla, L., \& Morgado, I. Un programador sencillo para el condicionamiento operante. Revista de Psicología General y Aplicada, 1976, 138, 81-84.

GaUSCILLO, E. H. Retrograde amnesia induced by electroconvulsive shock and carbon dioxide anesthesia in rats: An attempt to stimulate recovery. Journal of Comparative and Physiological Psychology, 1971, 75, 136-140.

Hull, C. L. Principles of behavior. New York: Appleton-CenturyCrofts, 1943.

KEYES, J. B. ECS perseveration effect following varying amounts of training. Physiological Psychology, 1973, 1, 2-4.

KeYeS, J. B., \& Young, A. G. ECS effects: The PRE. Bulletin of the Psychonomic Society, 1973, 1, 39-40.

Mille R, A. J. Variations in retrograde amnesia parameters of electroconvulsive shock and time of testing. Journal of Comparative and Physiological Psychology, 1968, 66, 40-47.

Missanin, J. R., Smith, N. F., \& Miller, R. R. Memory of electroconvulsive shock as a function of intensity and duration. Psychonomic Science, 1971, 22, 5-7.

Routtenberg, A., \& KAY, K. E. Effects of one electroconvulsive shock seizure on rat behavior. Journal of Comparative and Physiological Psychology, 1965, 59, 285-288.

Thompson, R., \& Dean, W. A. A further study of retroactive effects of ECS. Journal of Comparative and Physiological Psychology, 1955, 48, 488-491.

(Received for publication March 12, 1979; revision accepted June $18,1979$. 